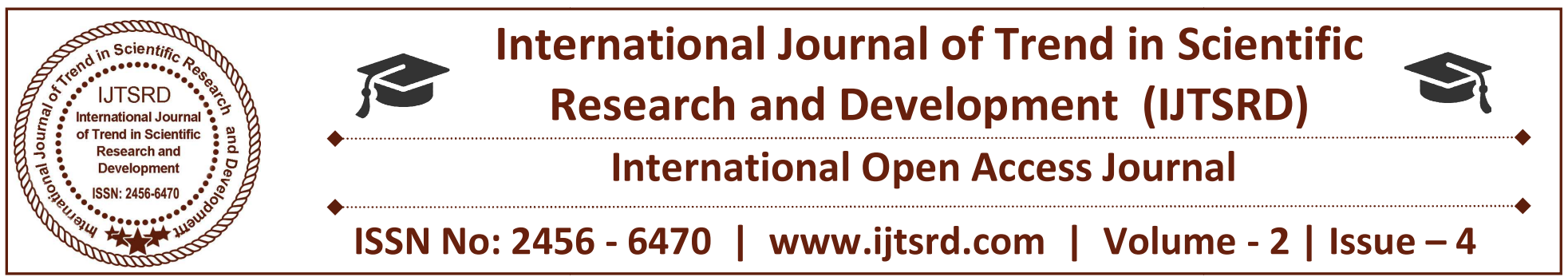

\title{
Parametric Analysis of Reciprocating Friction and Wear Behaviour of PTFE Composite
}

\author{
Pawan I. Patel ${ }^{1}$, Mr. Hemant Bhore ${ }^{2}$, Dr. R. R Arakerimath ${ }^{3}$ \\ ${ }^{1}$ M.Tech Mechanical (CADME), ${ }^{2}$ Asst Professor, ${ }^{3}$ HOD Mechanical Department, \\ G.H. Raisoni College of Engineering \& Management, Wagholi, Pune, Maharashtra, India
}

\begin{abstract}
When filler materials like carbon, graphite, glass fibres are added in the PTFE, a composite is formed which improves mechanical \& thermal properties of that composite. It increases hardness and wear resistance, while the coefficient of friction is slightly affected and remains low. In this survey, we study various papers in which various methods \& experiments were carried out for calculating friction $\&$ wear resistance of various compositions of polymers. So it is easy to understand properties \& behaviour of polymers under various test conditions.
\end{abstract}

Keywords: Composites, PTFE, friction, wear

\section{INTRODUCTION}

Polytetrafluoroethylene (PTFE) is an important polymer based engineering material. When rubbed against a hard surface, PTFE exhibits a low coefficient of friction but a high rate of wear. It is white or gray in color. It is an ideal bearing material for heavy and light load pressures with medium and low surface speeds. The development of the fluoropolymer industry began with the discovery of the polytetrafluoroethylene (PTFE) by Dr. Roy J. Plunkett (1910-1994) at DuPont in 1938 and introduction as a commercial product in 1946.Polytetrafluoroethylene (PTFE) is a highperformance engineering plastic which is widely used in industry due to its properties of self-lubrication, low friction coefficient, high temperature stability and chemically resistant. While PTFE exhibits poor wear and abrasion resistance, leading to early failure and leakage problem in the machine parts.
To minimize this problem, various suitable fillers added to PTFE. Generally, reinforcements such as glass fibres, carbon fibres and solid lubricants are added internally or incorporated into the PTFE. Its relative softness and poor heat conductivity limit its suitability as a bearing material to applications involving low speeds and low unit pressure, the tribological behaviour of polymers is affected by environmental and operating conditions and by the type, size, amount, shape and orientation of the fibres.

A relationship between the wear of the polymers and operating parameters is desirable to obtain the better understanding on the wear behaviour. In 1953, a new fluoropolymer, polychlorotrifluoroethylene (PCTFE) was commercialized by M. W. Kellog Company under the trade mark Kel-F. PCTFE is produced by the free radical polymerization of chlorotrifluoroethylene (CTFE) with a linear polymer chain structure.

Polytetrafluoroethylene (PTFE) polymer is a widely used solid lubricant. It is commonly used to provide a dry sliding friction coefficient $\mu<0.2$ on a variety of counterface types including stainless steel. PTFE is a popular polymer solid lubricant because of its resistance to chemical attack in a wide variety of solvents and solutions, high melting point, low coefficient of friction, and biocompatibility.

It is commonly used in bearing and seals applications. Unfortunately, PTFE suffers from poor wear resistance. Gong et al. and Blanchet and Kennedy report unfilled wear-rates of $7.36 \times 10-4$ and $7.41 \times 10-4 \mathrm{~mm} 3 / \mathrm{Nm}$, respectively. A hypothesis for 
the low friction of PTFE is that the long chains of PTFE, $-(\mathrm{CF} 2-\mathrm{CF} 2) n-$, orient on the transfer surface during sliding, forming a low shear-strength interface with the bulk PTFE bearing material. PTFE has a 13/1 or $15 / 1$ helicalmolecular structure with the fluorine atoms close enough to form a smooth cylindrical surface against which other molecules can easily slide .Hard particulate fillers made of ceramic or metal particles, and fiber fillers made of glass have been used with a PTFE matrix to dramatically improve the wear resistance, even up to three orders of magnitude. The use of such hard particles increases the dry sliding friction coefficient and abrades the counterface. Counterface abrasion is not desirable in a solid lubricant bearing system. Novel non-abrasive PTFE systems with wear resistance similar to filled PTFE composites have been made using gamma and electron irradiation by Briscoe and $\mathrm{Ni}$ and Blanchet and Peng respectively. With the recent availability of nanoparticles it is hypothesized that composites made with such small fillers will be significantly less abrasive than their micrometer sized counterparts. Perhaps such composites will provide a new family of non-abrasive and wear-resistant solid lubricant bearing materials.

\subsection{Test Conditions:}

- Load: Load is important factor when we consider friction \& wear. As we know Friction \& wear is directly proportional to the applied load.

- Velocity: When it's deal with friction and wear testing machine, it is very necessary to consider the velocity of the specimen. Generally, frictional resistance decreases with increasing velocity.

- Temperature: Environmental temperature also affects the accuracy of the experiment.

- Contact Area: Contact area between mating parts is important. Contact area in all conditions must be same.

\subsection{Properties to Study:}

PTFE has good properties such as :

- Coefficient of friction.

- Wear rate, heat resistance.

- Electrical insulation properties and chemical inertness.

- $\quad$ PTFE + Carbon Composite.

- $\quad$ PTFE + Bronze Composite.

- Non- Adhesive properties

- Very low friction.
1.3 Parameters To Reduce Friction/Wear.

- Load.

- Velocity.

- Temperature.

- Contact Area.

- Surface Finish.

- Sliding Distance.

- Environment.

- Material

- Hardness of counter face.

The Piston on Cam $\mathrm{n}$ follwer wear testing machine represents a substantial advance in terms of simplicity and convenience of operation, ease of specimen clamping and accuracy of measurements, both of Wear \& Frictional force.

\subsubsection{Coefficient of Friction}

The coefficient of friction is generally depends on the Load, sliding speed. Material should possess low coefficient of friction.

\subsubsection{Wear rate}

Wear is the removal of material from either or both of the contacting surfaces. Material should have improved wear resistance under load and permanent deformation.

\section{LITERATURE REVIEW}

[1] H. unal et al (2004) "Sliding friction and wear behaviour of polytetrafluoroethylene and its composites under dry conditions" in Materials and Design 25 (2004) 239-245 presented the influence of test speed and load values on the friction and wear behaviour of pure polytetrafluoroethylene (PTFE), glass fibre reinforced (GFR) and bronze and carbon (C) filled PTFE polymers under ambient conditions in a pin-on-disc arrangement concluded that The friction coefficient of pure PTFE and its composites decreases when applied load increases also pure PTFE is characterised by high wear because of its small mechanical properties. Therefore, the reinforcement PTFE with glass fibres improves the load carrying capability that lowers the wear rate of the PTFE.

[2] Ayman A. Aly, et al (2012) "Friction and Wear of Polymer Composites Filled by Nano-Particles: A Review", World Journal of Nano Science and Engineering, 2012, 2, 32-39 has reviewed about friction \& wear effects on nano particles filled composites. The survey showed that there is a 
significant improvement in mechanical properties of the composite due to the addition of the nanoparticles. Many types of nanofilling martials, including $\mathrm{SiC}$, $\mathrm{Si3N} 4, \mathrm{SiO} 2, \mathrm{ZrO} 2, \mathrm{ZnO}, \mathrm{CaCO} 3, \mathrm{Al} 2 \mathrm{O} 3, \mathrm{TiO} 2$, and nano-CuO, have been used to different types of polymers such as PEEK, PMMA, PTFE and epoxy. The mechanical properties which have been improved include fatigue resistance, fracture toughness, tensile strength, wear resistance, and friction coefficient.

[3] David L. Burris et al (2006) "A low friction and ultralow wear rate PEEK/PTFE composite", Science Direct, Wear 261 (2006) 410-418 presented PEEK filled PTFE composite that exhibits low friction and ultra-low wear by using laboratory designed linear reciprocating tribometer and states that this composite material has a friction coefficient \& wear rate lower than unfilled PTFE and PEEK for every sample tested.

[4] Li Chang et al (2010)"Enhancement effect of nanoparticles on the sliding wear of short fiberreinforced polymer composites: A critical discussion of wear mechanisms" Tribology International 43 (2010) 2355-2364 investigated the wear mechanisms of the hybrid SFRPs filled with nano particles on pin on disc arrangement. It was found that the load carrying capacity of the SFRPs is mainly determined by the properties of the fibers. However, the tribological performance of SFRPs can be significantly improved by using nanoparticles due to their friction reducing abilities, especially under extreme loading conditions.

[5] N.V. Klaas, et al(2005) "The tribological behaviour of glass filled Polytetrafluroethylene", Tribology International 38 (2005) 824-833 has tested glass filled PTFE by using reciprocating wear tester apparatus under and concluded that The wear rate of PTFE composites was an order of two magnitude higher in water than under dry sliding conditions.

\section{METHODOLOGY}

Various test methods are available for friction \& wear testing. Some of them are explained below,

- The influence of test speed and load values on the friction and wear behaviour of pure polytetrafluoroethylene (PTFE), glass fibre reinforced (GFR) and bronze and carbon (C) filled PTFE polymers under ambient conditions in a reciprocating motion piston arrangement. 
International Journal of Trend in Scientific Research and Development (IJTSRD) ISSN: 2456-6470

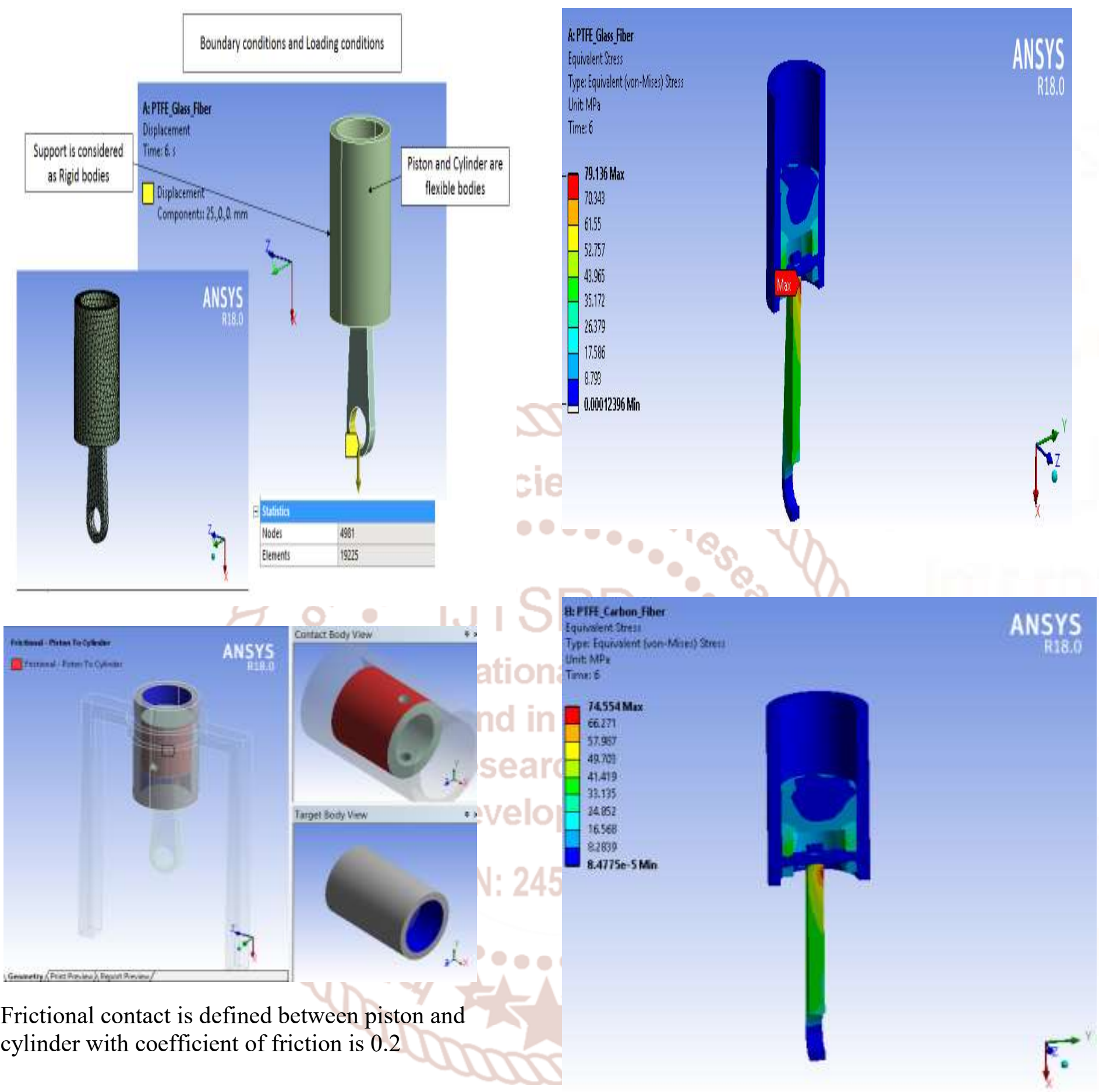




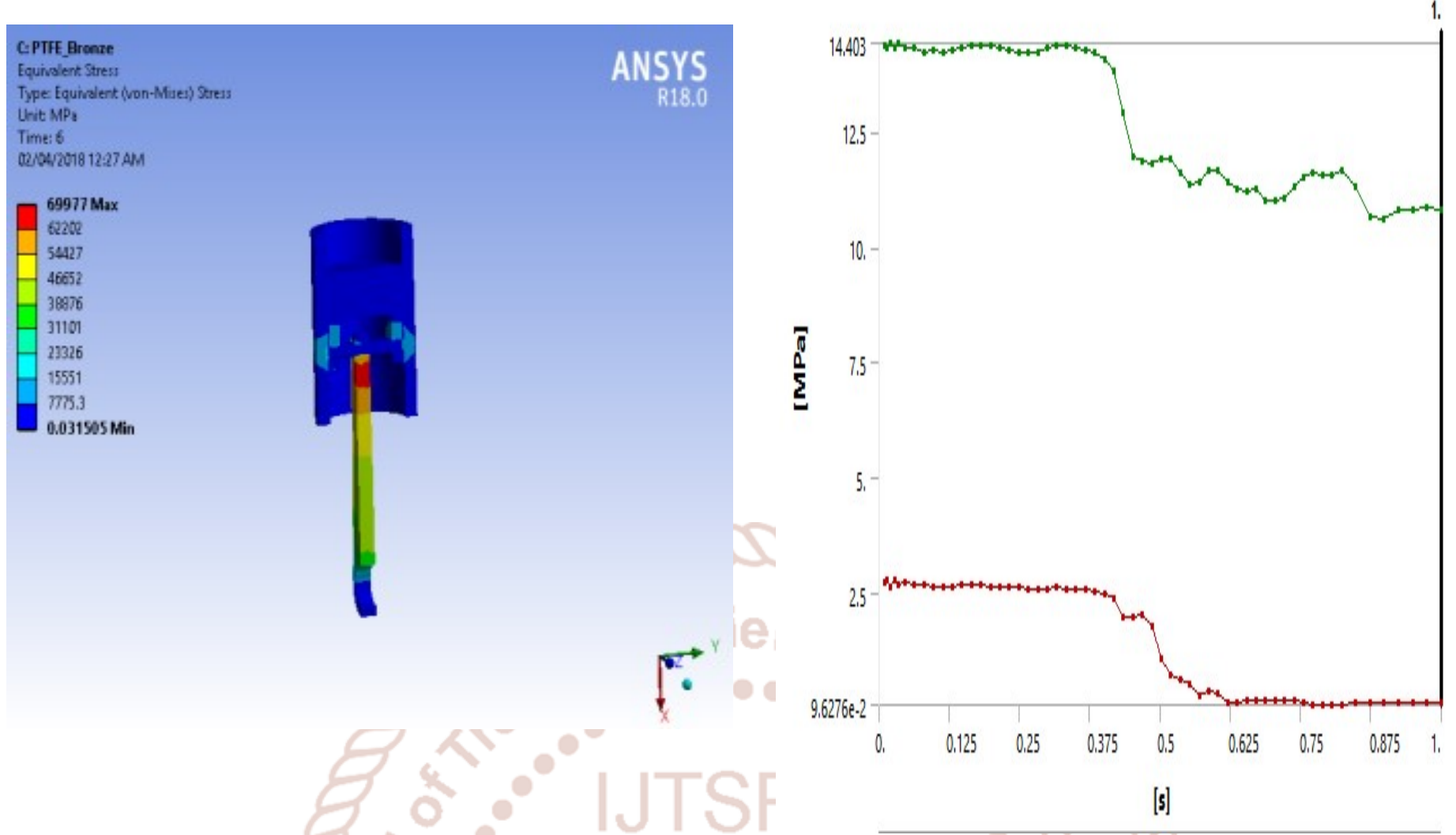

This is Von-Mises stress plot. As expected the stress decreased after the volume wear out

\begin{tabular}{|l|l|l|l|l|l|}
\hline Sr.No & \multicolumn{1}{|c|}{ Material } & $\begin{array}{l}\text { Revolution } \\
\text { of motor }\end{array}$ & $\begin{array}{c}\text { Orrignal } \\
\text { weight of } \\
\text { speciman }\end{array}$ & $\begin{array}{c}\text { New weight } \\
\text { of Speciman }\end{array}$ & $\begin{array}{l}\text { Reduction } \\
\text { in weight }\end{array}$ \\
\hline 1 & PTFE Glass Fibre & 50 & 170 & 169 & $\mathbf{1}$ \\
\hline 2 & PTFE Carbon Fibre & 50 & 110 & 109.7 & $\mathbf{0 . 3}$ \\
\hline 3 & PTFE Bronze Fibre & 50 & 120 & 118.5 & $\mathbf{1 . 5}$ \\
\hline 4 & PTFE Glass Fibre & 100 & 170 & 168.8 & $\mathbf{1 . 2}$ \\
\hline 5 & PTFE Carbon Fibre & 100 & 110 & 109.7 & $\mathbf{0 . 3}$ \\
\hline 6 & PTFE Bronze Fibre & 100 & 120 & 118 & $\mathbf{2}$ \\
\hline 7 & PTFE Glass Fibre & 150 & 170 & 168.5 & $\mathbf{1 . 5}$ \\
\hline 8 & PTFE Carbon Fibre & 150 & 110 & 109.5 & $\mathbf{0 . 5}$ \\
\hline 9 & PTFE Bronze Fibre & 150 & 120 & 117.8 & $\mathbf{2 . 2}$ \\
\hline
\end{tabular}




\section{RESULTS}
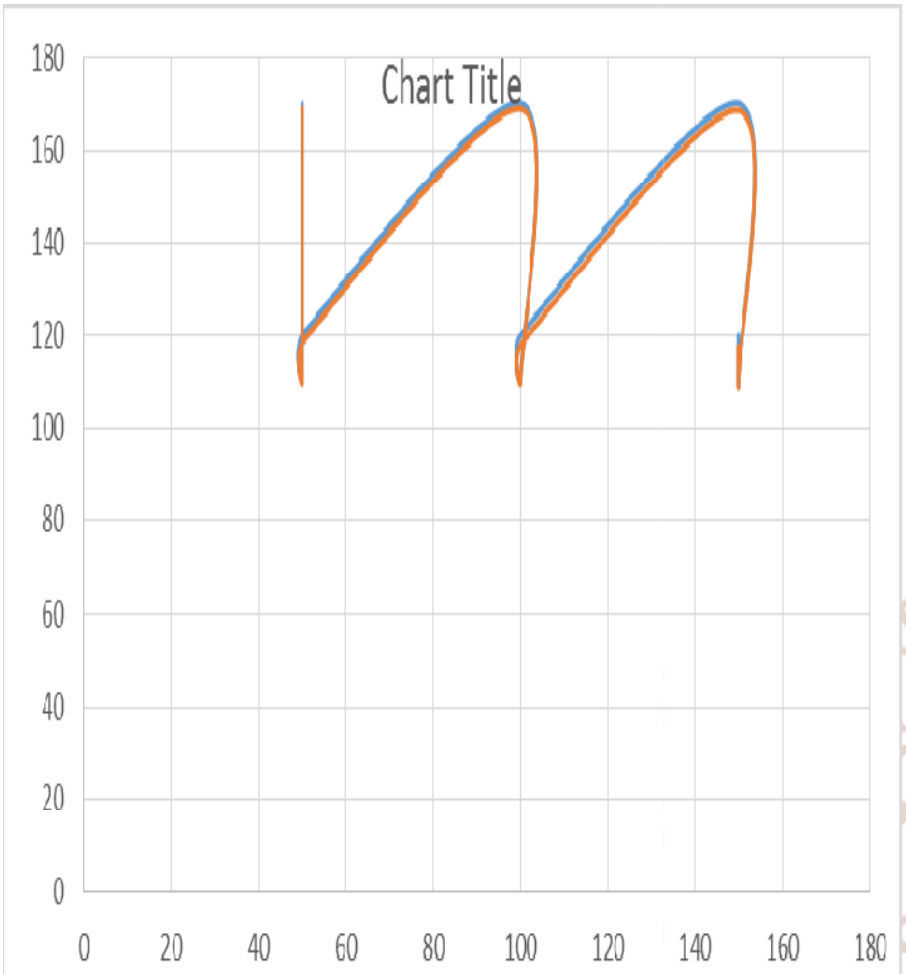

—Orrignal weight of speciman —New weight of Speciman

\section{CONCLUSION}

From the overview of above study concludes that,

1. Addition of filler materials such as bronze and carbon to PTFE causes an increase in wear resistance, while the coefficient of friction is slightly affected.

2. The friction coefficient of pure PTFE and its composites decreases by increasing applied load, which can be improved by reinforcement PTFE with glass fibres.

3. For the specific range of load and speed, the load has stronger effect on the wear behaviour of PTFE and its composites than the reciprocating velocity.

4. Addition of filler materials such as carbon, graphite, glass fibers and PPDT to PTFE causes an increase in hardness and wear resistance, while the coefficient of friction is slightly affected and remains low. Filler materials in general are effective in impeding large-scale fragmentation of PTFE, thereby reducing the wear rate.

\section{REFERENCES}

[1] H. Unal, A. Mimaroglu, U. Kadioglu, H. Ekiz, "Sliding friction and wear behaviour of Polytetrafluroethylene and its composites under dry conditions", Materials and Design 25 (2004) 239-245.

[2] Ayman A. Aly, El-Shafei B. Zeidan, AbdAllah A. Alshennawy, Aly A. El-Masry, Wahid A. Wasel, "Friction and Wear of Polymer Composites Filled by Nano-Particles: A Review", World Journal of Nano Science and Engineering, 2012, 2, 32-39.

[3] David L. Burris, W. Gregory Sawyer, "A low friction and ultra low wear rate PEEK/PTFE composite", Science Direct, Wear 261 (2006) 410418.

[4] Talat Tevrüz, "Tribological behaviors of carbon filled Polytetrafluoroethylene (PTFE) dry journal bearings", Wear 221 (1998) 61-68.

[5] Li Chang, Klaus Friedrich "Enhancement effect of nanoparticles on the sliding wear of short fiberreinforced polymer composites: A critical discussion of wear mechanisms" Tribology International 43 (2010) 2355-2364.

[6] N.V. Klaas, K. Marcus, C. Kellock, "The tribological behaviour of glass filled Polytetrafluroethylene", Tribology International 38 (2005) 824-833.

[7] W. Gregory Sawyer, Kevin D. Freudenberg, Praveen Bhimaraj, Linda S. Schadler, "A study on the friction and wear behavior of PTFE filled with alumina nanoparticles", Science Direct, Wear 254 (2003) 573-580.

[8] Deepak Bagale, Sanjay Shekhawat, Jitendra Chaudhari, "Wear Analysis of Polytetrafluoroethylene and its Composites under Dry Conditions using Design-Expert", International Journal of Scientific and Research Publications, Volume 3, Issue 1, January 2013, ISSN 22503153.

[9] Jaydeep Khedkar, Ioan Negulescu, Efstathios I. Meletis, "Sliding wear behavior of PTFE composites", Wear 252 (2002) 361-369. 